\title{
Regulation of transferrin receptor-1 mRNA by the interplay between IRE-binding proteins and miR-7/miR-141 in the $3^{\prime}$-IRE stem-loops
}

\author{
MASAKI MIYAZAWA, ${ }^{1}$ ALEXANDER R. BOGDAN, ${ }^{1}$ KAZUNORI HASHIMOTO, and YOSHIAKI TSUJI \\ Department of Biological Sciences, Toxicology Program, North Carolina State University, Raleigh, North Carolina 27695, USA
}

\begin{abstract}
Intracellular iron is tightly regulated by coordinated expression of iron transport and storage genes, such as transferrin receptor-1 (TfR1) and ferritin. They are primarily regulated by iron through iron-induced dissociation of iron-regulatory proteins (IRPs) from iron-responsive elements (IREs) in the $3^{\prime}$-UTR (untranslated region) of TfR1 or 5'-UTR of ferritin mRNA, resulting in destabilization of TfR1 mRNA and release of ferritin translation block. Thus high iron decreases iron transport via TfR1 mRNA degradation and increases iron storage via ferritin translational up-regulation. However, the molecular mechanism of TfR1 mRNA destabilization in response to iron remains elusive. Here, we demonstrate that miR-7-5p and miR-141-3p target $3^{\prime}$-TfR1 IREs and down-regulate TfR1 mRNA and protein expression. Conversely, miR-7-5p and miR-141-3p antagomiRs partially but significantly blocked iron- or IRP knockdown-induced down-regulation of TfR1 mRNA, suggesting the interplay between these microRNAs and IRPs along with involvement of another uncharacterized mechanism in TfR1 mRNA degradation. Luciferase reporter assays using 3'-UTR TfR1 IRE mutants suggested that the IREs $C$ and $E$ are targets of miR-7-5p and miR-141-3p, respectively. Furthermore, miR-7 expression was inversely correlated with TfR1 mRNA in human pancreatic adenocarcinoma patient samples. These results suggest a role of microRNAs in the TfR1 regulation in the IRP-IRE system.
\end{abstract}

Keywords: iron; IRP; IRE; miR-7; microRNA

\section{INTRODUCTION}

Iron is indispensable for cell growth, division, and survival, but excess iron can be toxic to cells through catalyzing the formation of reactive oxygen species (ROS) via Fenton chemistry (Dixon and Stockwell 2014). ROS serve as an important signaling molecule through oxidative regulation of various enzymes and transcription factors (Ray et al. 2012), but in excess cause oxidation of macromolecules such as proteins, lipids, and nucleic acids (Jomova and Valko 2011). Oxidative stress-mediated cell damage has been implicated in the development of various human diseases (Ghezzi et al. 2017; Poprac et al. 2017). Conversely, iron deficiency causes anemia and nutritional disorders (Hentze et al. 2010). Furthermore, the availability of body iron in cells and tissues significantly impacts host-pathogen interactions (Wilson et al. 2016). As such, cells have evolved a robust post-transcriptional regulatory system that tightly controls iron import, export, and storage (Bogdan et al. 2016; Muckenthaler et al. 2017). This regulatory system involves the in-

\footnotetext{
${ }^{1}$ These authors contributed equally to this work.

Corresponding authors: ytsuji@ncsu.edu, m.miyazawa@live.jp

Article is online at http://www.rnajournal.org/cgi/doi/10.1261/rna. 063941.117.
}

teraction of iron-responsive elements (IREs), conserved stem-loop sequences in the untranslated regions (UTRs) of several iron metabolism mRNAs, and the iron-regulatory proteins (IRPs), comprising IRP1 and IRP2 (Anderson et al. 2012; Kühn 2015). In low iron conditions, IRPs bind tightly to IREs on target mRNAs; upon iron increase, the IRPs dissociate from the IREs and either form cytosolic aconitase (IRP1) or are degraded by the proteasome (IRP2) (Rouault 2006; MacKenzie et al. 2008). This regulatory system, termed the IRE-IRP system, is well conserved in evolution and is found in all chordates (Theil 1994; Piccinelli and Samuelsson 2007).

Transferrin receptor-1 (TfR1, TFRC) is the main cellular iron importer in many cell types, and is found in all vertebrate taxa (Lambert 2012). TfR1 is a dimeric transmembrane protein that can bind extracellular transferrin (Tf), a serum protein that acts as an iron carrier. The TfR1/Tf complex is internalized via endocytosis, followed by release of iron

\footnotetext{
(C) 2018 Miyazawa et al. This article is distributed exclusively by the RNA Society for the first 12 months after the full-issue publication date (see http://rnajournal.cshlp.org/site/misc/terms.xhtml). After 12 months, it is available under a Creative Commons License (Attribution-NonCommercial 4.0 International), as described at http://creativecommons.org/licenses/bync/4.0/.
} 
from Tf and DMT1-mediated delivery of iron into the cell (Bogdan et al. 2016). The endosome re-fuses with the plasma membrane, and TfR 1 and Tf are recycled (MacKenzie et al. 2008). The expression of TfR 1 is regulated post-transcriptionally by the IRE-IRP system and is inversely correlated with cellular iron status; TfR1 expression is high during iron deficiency, whereas high iron leads to lower TfR1 expression (Casey et al. 1988; Anderson et al. 2012; Kühn 2015). TfR1 is unique in that its transcript contains five IREs (termed AE) located within an $\sim 700$ nucleotide region in the $3^{\prime}$-UTR (Casey et al. 1988; Müllner and Kühn 1988). During iron deficiency, the IRE-IRP association stabilizes TfR1 mRNA; after IRP dissociation during iron excess, TfR 1 mRNA is destabilized and degraded (Müllner et al. 1989). Early studies into TfR 1 mRNA stability suggested that an endonuclease cleavage within the IRE region is responsible for TfR 1 mRNA decay after IRP dissociation (Binder et al. 1994); however, almost three decades after the initial observation of TfR 1 mRNA destabilization upon IRP dissociation (Casey et al. 1988; Müllner and Kühn 1988), no effector molecule or degradation pathway in the IRP-IRE regulatory system has been determined.

MicroRNAs (miRNAs or miRs) are short, single-stranded, noncoding RNAs. After long primary microRNA transcripts are processed by Drosha and Dicer, mature microRNAs (20$22 \mathrm{nt}$ in length) are incorporated into the miRNA-induced silencing complex (miRISC), a large complex of proteins involved in post-transcriptional gene silencing (Fabian and Sonenberg 2012; Hayes et al. 2014; Iwakawa and Tomari 2015). MicroRNAs direct the miRISC to a target mRNA by base-pairing to sites in the $3^{\prime}$-UTR of mRNAs that are complementary to the miRNA "seed region" (nucleotides 2-7), an essential sequence for miRNA function (Lewis et al. 2005). Once associated with a target mRNA, the miRISC down-regulates expression through blocking translation or inducing degradation of target transcripts (Fabian and Sonenberg 2012; Hayes et al. 2014; Iwakawa and Tomari 2015). Because only the short seed region requires full complementarity, each miR has dozens of potential targets that must be experimentally verified (Brennecke et al. 2005).

Given that TfR1 mRNA is degraded when IRPs dissociate from the $3^{\prime}$-IREs in high iron conditions, we hypothesized that miRNAs may be involved in TfR1 mRNA degradation when IRP is dissociated from the TfR1 IREs in iron-replete cells. We show that the TfR 1 mRNA IREs contain several conserved miRNA target sites within the IRE sequences, and demonstrate a novel role for miR-7-5p and miR-141$3 p$ in down-regulating TfR1 mRNA expression via the interplay with IRPs.

\section{RESULTS}

Since its initial discovery almost 30 years ago (Owen and Kuhn 1987; Casey et al. 1988; Müllner and Kühn 1988; Müllner et al. 1989), follow-up studies on the molecular mechanism of TfR 1 mRNA stability regulation through the IRE-IRP system have been rarely published. Therefore, we first tried to verify that the IRP-IRE system is tightly regulated by iron in our study using two human cell lines; K562 human erythroleukemia cells that were extensively used for earlier TfR1 expression studies (Bridges and Cudkowicz 1984; Mattia et al. 1984; Rao et al. 1985; Rouault et al. 1985) leading to the discovery of the IRE-IRP system, and SW480 human colon adenocarcinoma cells primarily used throughout this study because expression of epidermal growth factor receptor-1 (EGFR1) (a positive control for miR-7 activity [Webster et al. 2009]) was detectable in SW480 but not in K562 cells (see below).

\section{Expression of TfR1 mRNA is regulated by iron and the IRE/IRP interaction at the post-transcriptional level}

We first surveyed expression of TfR 1 mRNA and protein in response to cellular iron status in SW480 and K562 cells. They were treated with increasing concentrations of iron (ferric ammonium citrate $[\mathrm{FAC}]$, a soluble form of iron) or iron chelator (deferoxamine mesylate [DFO]) for $24 \mathrm{~h}$. As expected, TfR1 mRNA and protein in SW480 (Fig. 1A) and K562 cells (Fig. 1B) decreased in a dose-dependent manner after FAC treatment and increased after DFO treatment, whereas the iron storage protein ferritin $\mathrm{H}$ showed the opposite response. To measure the stability of TfR 1 mRNA after iron treatment, SW480 cells were cotreated with the transcription inhibitor 5,6-dichloro-1- $\beta$-D-ribofuranosyl-1H-benzimidazole (DRB) and FAC or vehicle. The half-life of TfR1 mRNA in FAC-treated SW480 cells decreased to $\sim 4 \mathrm{~h}$, compared with $>8 \mathrm{~h}$ in the vehicle-treated cells (Fig. 1C). FAC treatment had no effect on the half-life of a control mRNA, TATA binding protein (TBP) (Fig. 1C), suggesting that FAC is causing a destabilization of TfR1 mRNA in SW480 (and K562 cells as previously characterized in Rouault et al. 1988). Consistently, binding of IRP1 and IRP2 to TfR1 IREs was significantly decreased in SW480 after 1-3 h FAC treatment, with no alteration of expression of IRP1 but a concomitant decrease of IRP2 protein (Fig. 1D). IRP2 decrease in high-iron conditions is attributable to the action of FBXL5, an iron-sensitive E3 ubiquitin ligase that marks IRP2 for proteasomal degradation (Salahudeen et al. 2009; Vashisht et al. 2009). In addition, knocking down IRP1 and IRP2 decreased TfR1 mRNA expression in SW480 (Fig. 1E), suggesting that IRP1 and IRP2 act as stabilizing proteins on TfR1 mRNA. Collectively, the IRP-IRE system is functioning properly in response to high and low iron conditions in our experimental set-up.

\section{miR-7-5p and miR-141-3p down-regulate TfR1 mRNA}

Given the importance of the IREs in determining TfR 1 mRNA stability, we closely investigated the IREs for any sequences that may be targeted by known mRNA degradation 
A
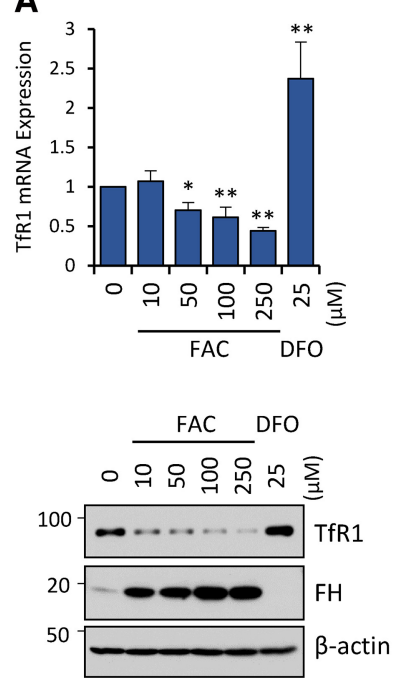

B
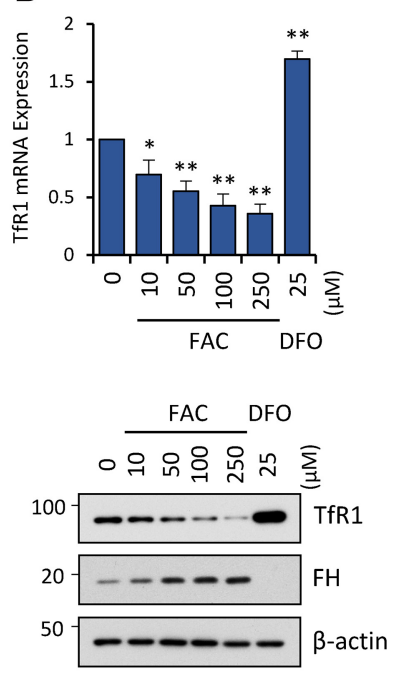

C
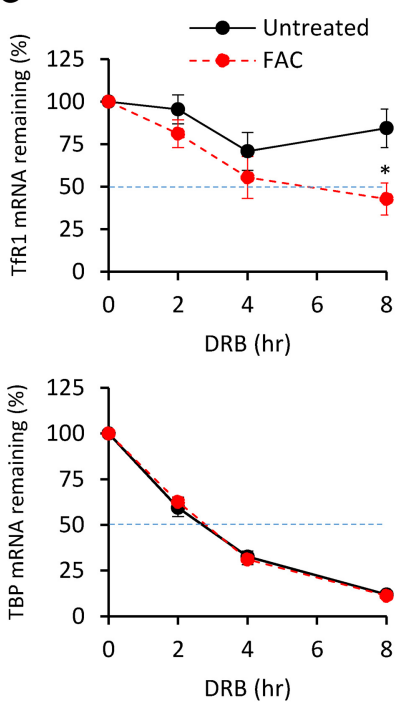

E

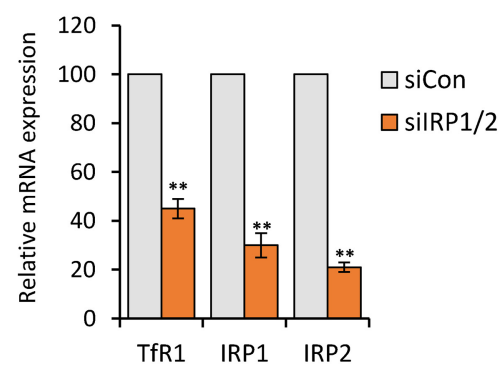

FIGURE 1. TfR1 mRNA stability is controlled by the iron-sensitive IRE-IRP interaction. $(A, B)$ TfR1 mRNA and protein expression in iron-replete and iron-deficient conditions in SW480 $(A)$ and K562 $(B)$ cells. Cells were treated with 0, 10, 50, 100, and $250 \mu \mathrm{M}$ ferric ammonium citrate (FAC) or $25 \mu \mathrm{M}$ iron chelator deferoxiamine (DFO) for $24 \mathrm{~h}$. Expression of TfR1 mRNA and protein was measured by quantitative real-time PCR (qPCR) and western blotting, respectively. TfR1 mRNA expression was normalized to GAPDH mRNA, and $\beta$-actin was used as a loading control for western blotting. Results are from three independent experiments. Representative western blots and qPCR means \pm SE are shown. $\left(^{*}\right) P<0.05,\left({ }^{* *}\right) P<0.01$ versus untreated cells. $(C)$ SW480 cells were treated with $30 \mu \mathrm{g} / \mathrm{mL}$ transcription inhibitor (5,6-dichloro-1- $\beta$-D-ribofuranosyl-1H-benzimidazole; DRB) and vehicle or $250 \mu \mathrm{M}$ FAC for $0,2,4,6$, or $8 \mathrm{~h}$. TfR 1 and TBP percent mRNA remaining were determined by qPCR and normalized to $0 \mathrm{~h}(100 \%$ mRNA remaining). Results are from five independent experiments. Means \pm SE are shown. (D) Cell lysates isolated from SW480 cells treated with $250 \mu \mathrm{M}$ FAC for the indicated times were incubated with no probe (each first left lane) or biotinylated TfR1 IRE C or IRE E RNA probe (see Materials and Methods for sequences) for $2 \mathrm{~h}$ and precipitated with streptavidin-sepharose beads. The precipitates were subjected to western blotting with anti-IRP1 or anti-IRP2 antibody. Experiments were repeated three times and representative blots are shown. $(E)$ SW480 cells were transfected with siCon or a combination of siIRP1 and siIRP2 (siIRP1/2) for $48 \mathrm{~h}$. TfR1, IRP1, and IRP2 mRNA expressions were determined by qPCR. Results are from three independent experiments. Means $\pm \mathrm{SE}$ are shown $\left(^{* *}\right) P<0.01$ versus siCon.

pathways. Using miRNA target prediction algorithms such as TargetScan and miRanda, we found three putative miRNA binding sites that were wholly contained within the IRE stem-loops. TargetScan (targetscan.org) can predict miRNA targeting of mRNAs by searching for conserved target sequences in $3^{\prime}$-UTRs that match the miRNA seed sequences (Agarwal et al. 2015). miR-124-3p, miR-7-5p, and miR-141-3p seed sequences have potential binding sites within IREs B, C, and E, respectively (Fig. 2A; Supplemental Table I). Since iron-mediated destabilization of TfR1 mRNA via the IRE-IRP system is well conserved throughout vertebrates, any proposed mechanism of TfR1 mRNA destabilization should likely be conserved in various species. We surveyed both the mature miRNA sequences (Table 1) and the potentially targeted TfR1 IRE sequences (Table 2) in various vertebrate species and found that both the miRNAs and the target IRE sequences were almost entirely conserved. Given the partial overlap in the IRP binding sites (a stabilizing force) and these putative miRNA target sites (a destabilizing force), we hypothesized that these miRNAs may be responsible for TfR1 mRNA destabilization through targeting the IRE sequences after iron-induced IRP dissociation. To test this hypothesis, SW480 cells were transfected with miRNA mimics for $2 \mathrm{~d}$ and were treated with FAC for 5 h. In untreated cells, TfR1 mRNA was significantly downregulated by miR-7-5p and miR-141-3p, and to a lesser 
A Iron Responsive Elements (IRE)
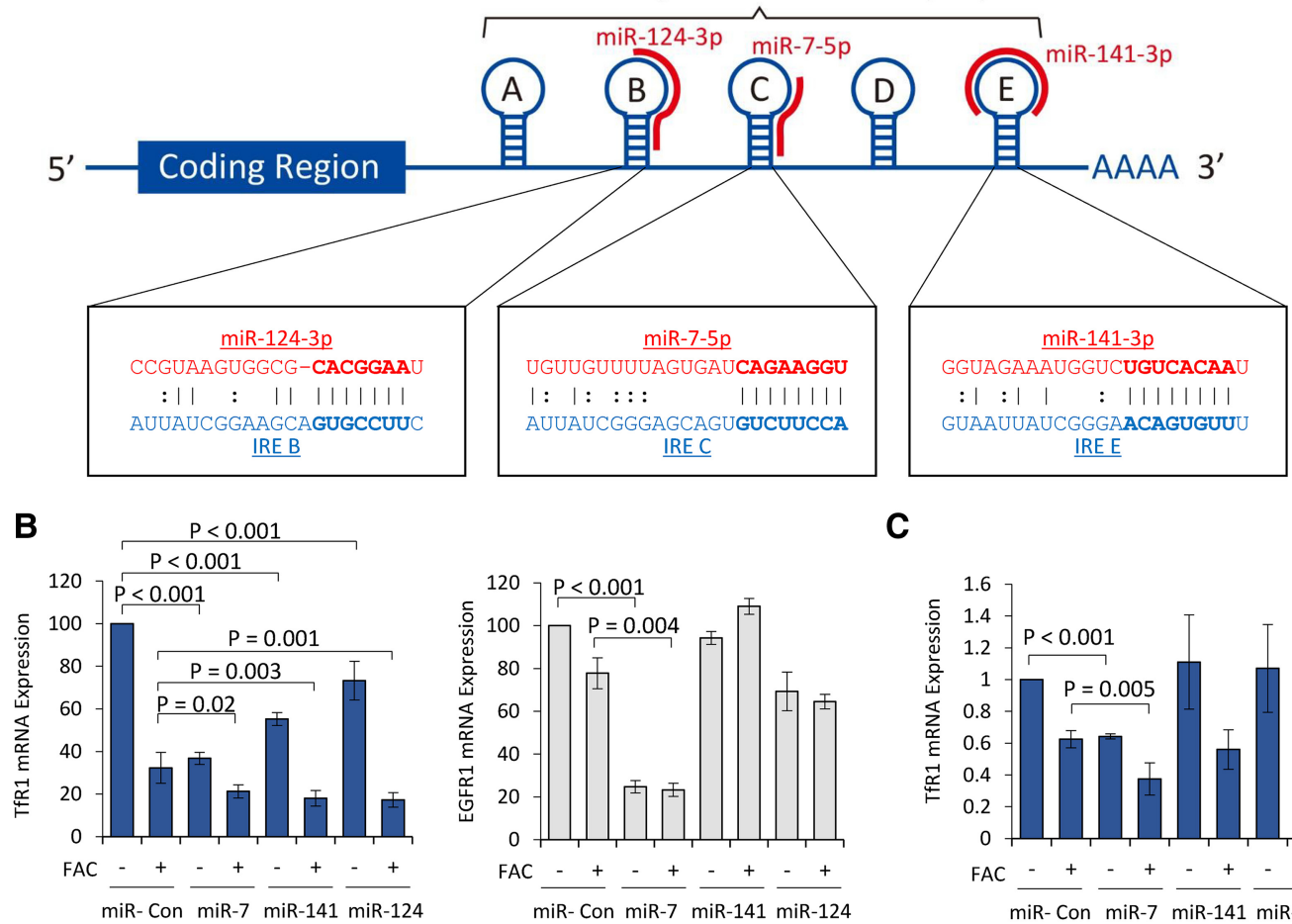

C

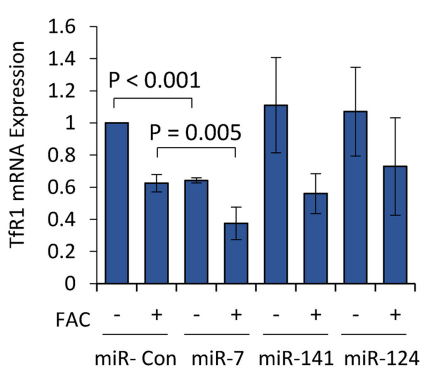

FIGURE 2. TfR1 mRNA contains several well-conserved microRNA target sites and is down-regulated by miR-7-5p and miR-141-3p. (A) Schematic showing miR-124-3p, miR-7-5p, and miR-141-3p target sites within TfR1 IREs B, C, and E, respectively. (B) SW480 or (C) K562 cells were transfected with miR-Con, miR-7-5p, miR-141-3p, or miR-124-3p for $48 \mathrm{~h}$. Transfected cells were then treated with vehicle or $250 \mu \mathrm{M} \mathrm{FAC} \mathrm{for} 5 \mathrm{~h}$. TfR1 and EGFR1 mRNA expression was measured by qPCR and normalized to HPRT1 expression. EGFR1 mRNA in K562 cells was undetectable in $C$. Experiments were repeated three times for SW480 and five times for K562 cells and qPCR means \pm SE are shown.

extent by miR-124-3p (Fig. 2B). FAC treatment down-regulated TfR1 mRNA compared to untreated control in all transfection conditions $(P<0.01)$, and all these miRNAs further down-regulated TfR1 mRNA compared to miR-Control. Epidermal growth factor receptor-1 (EGFR1), a known target of miR-7-5p (Webster et al. 2009), was down-regulated by miR-7-5p transfection but was unaffected by FAC treatment or miR-141-3p/miR-124-3p transfection (Fig. 2B), indicat- ing that the miRNA transfection was successful and that the microRNA mimics exhibited target specificity. Similar down-regulation of TfR 1 mRNA with miR-7-5p transfection was observed in K562 cells, while miR-141-3p and miR-124$3 p$ effects were not significant compared to scrambled control transfection (Fig. 2C). Collectively, these results suggest that miR-7-5p down-regulates TfR1 mRNA expression in multiple cell types.

TABLE 1. Conservation of mature microRNA sequences across various vertebrate species

\begin{tabular}{|c|c|c|c|c|}
\hline Species & $\begin{array}{c}\text { Common } \\
\text { name }\end{array}$ & miR-7 mature sequence & miR-141 mature sequence & miR-124 mature sequence \\
\hline Homo sapiens & Human & UGGAAGACUAGUGAUUUUGUUGU & UAACACUGUCUGGUAAAGAUGG & UAAGGCACGCGGUGAAUGCC \\
\hline Pan troglodytes & Chimpanzee & UGGAAGACUAGUGAUUUUGUUGU & UAACACUGUCUGGUAAAGAUGG & UUAAGGCACGCGGUGAAUGCCA \\
\hline Macaca mulatta & Rhesus & UGGAAGACUAGUGAUUUUGUUGU & AACACUGUCUGGUAAAGAUGG & UUAAGGCACGCGGUGAAUGCCA \\
\hline Mus musculus & Mouse & UGGAAGACUAGUGAUUUUGUUGU & UAACACUGUCUGGUAAAGAUGG & UAAGGCACGCGGUGAAUGCC \\
\hline Rattus norvegicus & Rat & UGGAAGACUAGUGAUUUUGUUGU & UAACACUGUCUGGUAAAGAUGG & UAAGGCACGCGGUGAAUGCC \\
\hline Canis familiaris & Dog & UGGAAGACUAGUGAUUUUGUUGU & AACACUGUCUGGUAAAGAUGG & UAAGGCACGCGGUGAAUGCCA \\
\hline Equus caballus & Horse & UGGAAGACUAGUGAUUUUGUUGU & UAACACUGUCUGGUAAAGAUGG & UAAGGCACGCGGUGAAUGCC \\
\hline Gallus gallus & Chicken & UGGAAGACUAGUGAUUUUGUUG & UAACACUGUCUGGUAACGAUGU & UUAAGGCACGCAGUGAAUGCCA \\
\hline Xenopus tropicalis & Frog & UGGAAGACUAGUGAUUUUGUUG & UAACACUGUCUGGUAACGAUGU & UUAAGGCACGCGGUGAAUGCCA \\
\hline Fugu rubripes & Pufferfish & UGGAAGACUAGUGAUUUUGUU & UAACACUGUCUGGUAACGAUGU & UAAGGCACGCGGUGAAUGCCAA \\
\hline Danio rerio & Zebrafish & UGGAAGACUAGUGAUUUUGUUGU & UAACACUGUCUGGUAACGAUGC & UAAGGCACGCGGUGAAUGCCAA \\
\hline
\end{tabular}


TABLE 2. Conservation of TfR1 IRE B, C, and E sequences across various vertebrate species

\begin{tabular}{|c|c|c|c|}
\hline Species & TfR1 IRE B & TfR1 IRE C & TfR1 IRE E \\
\hline Homo sapiens & AAUUAUCGGAAGCAGUGCCUUCCAUAAUU & CAUUAUCGGGAGCAGUGUCUUCCAUAAUG & AAUUAUCGGGAACAGUGUUUCCCAUAAUU \\
\hline Pan troglodytes & AAUUAUCGGAAGCAGUGCCUUCCAUAAUU & CAUUAUCGGGAGCAGUGUCUUCCAUAAUG & AAUUAUCGGGAACAGUGUUUCCCAUAAUU \\
\hline Mus musculus & AAUUAUCGGAAGCAGUGCCUUCCAUAAUU & CAUUAUCGGGAGCAGUGUCUUCCAUAAUG & AAUUAUCGGGAACAGUGUUUCCCAUAAUU \\
\hline Rattus norvegicus & AAUUAUCGGAAGCAGUGCCUUCCAUAAUU & CAUUAUCGGGAGCAGUGUCUUCCAUAAUG & AAUUAUCGGGAACAGUGUUUCCCAUAAUU \\
\hline Canis familiaris & AAUUAUCGGAAGCAGUGCCUUCCAUAAUU & CAUUAUCGGGAGCAGUGUCUUCCAUAAUG & AAUUAUCGGGAACAGUGUUUCCCAUAAUU \\
\hline Gallus gallus & AAUUAUCGGAAGCAGUGCCUUCCAUAAUU & CAUUAUCGGGGGCAGUGUCUUCCAUAAUG & AAUUAUCGGGGACAGUGUUUCCCAUAAUU \\
\hline Xenopus tropicalis & AAUUAUCGGAAGCAGUGCCUUCCAUAAUU & CAUUAUCGGAAGCAGUGUCUUCCAUAAUG & AAUUAUCGGGGACAGUGUUUCCCAUAAUU \\
\hline
\end{tabular}

\section{miR-7-5p and miR-141-3p target TfR1 mRNA through IRE $C$ and IRE $E$}

The down-regulation of TfR 1 mRNA by miR-7-5p and to a lesser extent by miR-141-3p transfection does not necessarily mean that these miRNAs are directly targeting TfR1 IRE sequences; miR-7-5p and miR-141-3p may be targeting a different site on TfR1 mRNA, or are down-regulating different genes that can modulate TfR 1 expression. To determine if miR-7-5p and miR-141-3p are acting through the putative target sites located in IREs $\mathrm{C}$ and $\mathrm{E}$, a reporter vector was constructed with a $\sim 700 \mathrm{bp}$ fragment containing the five TfR1 IREs cloned downstream from a luciferase gene. Site-directed mutagenesis was utilized to insert several mismatches into the putative miRNA target sites located in IREs $\mathrm{C}$ and $\mathrm{E}$ (Fig. 3A), disrupting any potential miRNA activity mediated through these sites. It should be noted that the mutant IRE C sequence still maintained normal IRP binding characteristics; IRPs exhibited strong binding in low iron conditions and dissociated in high iron conditions (Fig. 3B). In contrast, the mutant IRE E sequence lost the interaction with IRPs, indicating that this mutant IRE E should be more susceptible to miR-141-3p attack if possible because it is not protected by IRPs (Fig. 3B). Transfection of these IRE-luciferase reporters into SW480 cells followed by iron treatment (FAC $250 \mu \mathrm{M})$ demonstrated that the IRE-wild-type (WT) vector behaved similarly to endogenous TfR1 mRNA, showing a significant decrease in luciferase activity when treated with iron $\left({ }^{*} P<0.001\right)$ (Fig. 3C). Mutating IRE C (mutC) or IRE E (mutE) singly showed a partial inhibition of the iron response, while mutating both IRE $C$ and IRE E (mutC/E) eliminated the iron-induced decrease in luciferase activity (Fig. 3C). These data suggest that the miRNA target sites within IREs $\mathrm{C}$ and $\mathrm{E}$ are necessary for iron-mediated destabilization of TfR 1 mRNA. To confirm the results, we cotransfected miR-7-5p and miR-141-3p into wt- or mutant IRE C/E reporter-transfected cells with or without additional $250 \mu \mathrm{M}$ FAC treatment. The WT reporter showed a significant decrease in luciferase activity in FAC treated (siCon/FAC + ) or miR-7-5p and miR-141-3p (miR-7/-141) cotransfected cells (Fig. 3D). Treatment of FAC in miR-7/-141 transfected cells further decreased luciferase activity, suggesting the possibility of involvement of another uncharacterized mechanism in iron-induced TfR1 mRNA degradation. Mutating IREs $\mathrm{C}$ and $\mathrm{E}$ completely abol- ished the effects of FAC or miR-7-5p and miR-141-3p (Fig. 3D), suggesting that these miRNAs target TfR1 mRNA through IRE C and IRE E and mimicked the iron effect.

\section{Blocking endogenous miR-7-5p and miR-141-3p protects TfR1 mRNA from iron-induced degradation}

We further assessed our results that these miRNAs destabilize TfR1 mRNA in high-iron conditions. To this end, we attempted to block endogenous miR-7-5p and miR-141-3p with antagomiRs, highly specific inhibitors of individual miRNAs. First, the ability of antagomiRs to block mRNA degradation induced by miRNA transfection was assessed. To this end, we tested expression of EGFR1 mRNA as an established miR-7-5p target (Webster et al. 2009). The antagomiR for miR-7-5p (i7) prevented any decrease in EGFR1 mRNA expression induced by miR-7-5p transfection (Fig. 4A), indicating that antagomiR-7 was efficiently inhibiting miR-7-5p activity. Next, a combination of antagomiRs i7 and i141 were transfected into SW480 cells that were subsequently treated with vehicle or FAC to induce TfR1 mRNA degradation. While the antagomiR-transfected cells showed a notable but non-significant increase in basal TfR1 mRNA expression, the decrease of TfR1 mRNA in response to iron was partially but significantly blocked by these antagomiRs (Fig. 4B). The basal level of EGFR1 mRNA was rescued by the antagomiR7 and -141 , suggesting that antagomiR-7 is functional in this experiment (Fig. 4B). Additionally, we used a different manufacturer's antagomiR-7 and -141 to ensure that the suppression of TfR 1 mRNA degradation was not an artifact of the antagomiRs used in Figure 4A and B; indeed, we observed similar results with a second set of antagomiR-7 and -141 (Fig. 4C), despite the slight difference in the chemical modifications between the manufacturers' products.

Since the mature miR-7-5p, miR-141-3p, and the targeted TfR1 IRE sequences are conserved in various vertebrate species (Tables 1 and 2), along with the fact that the IRP-IRE system is also conserved, we tested the effect of the antagomiR combination on iron-induced TfR1 mRNA degradation in mouse NIH3T3 cells. The antagomiR-transfected NIH3T3 cells showed a significant increase in basal TfR1 mRNA expression, while TfR1 mRNA decrease following iron treatment was only partially rescued by these 
A

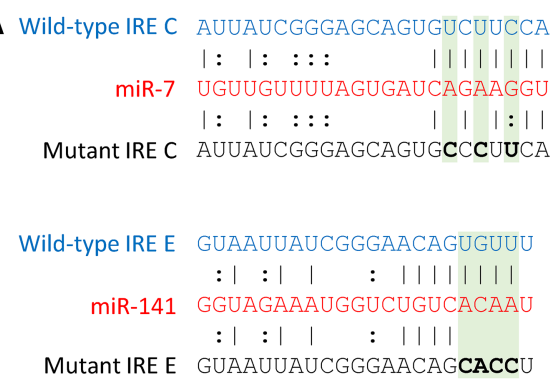

C

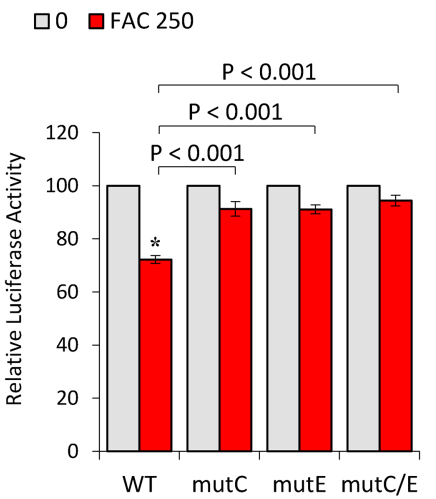

B

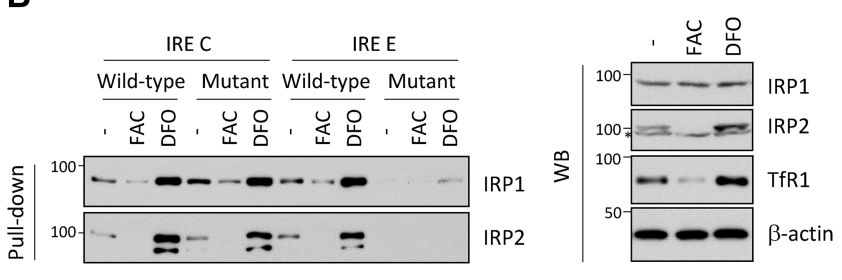

D

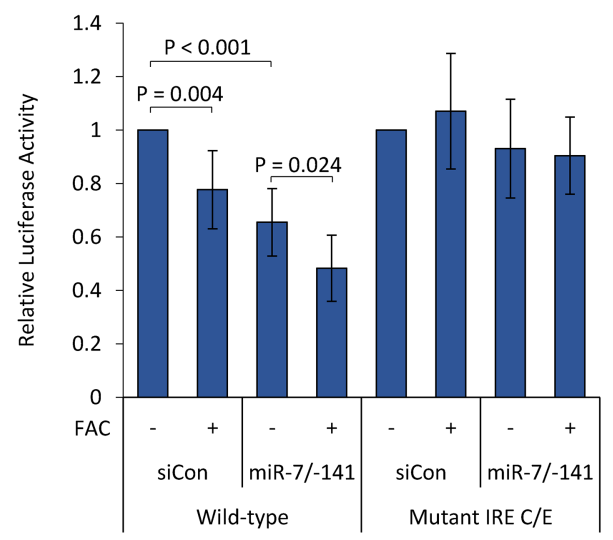

FIGURE 3. miR-7-5p and miR-141-3p target TfR1 mRNA through IRE C and IRE E. (A) An 700 bp fragment of TfR1 mRNA containing IREs A-E was cloned into the $3^{\prime}$-UTR cloning sites of pGL3-Promoter and pMIR-REPORT luciferase vectors. The miR-7-5p and miR-141-3p target sites located in IREs $\mathrm{C}$ and $\mathrm{E}$, respectively, were mutated by site-directed mutagenesis. Wild-type IRE sequences are shown above. (B) Cell lysates isolated from SW480 cells treated with $250 \mu \mathrm{M}$ FAC or $50 \mu \mathrm{M}$ DFO for $6 \mathrm{~h}$ were incubated with biotinylated wild-type or mutant IRE C or IRE E RNA for $3 \mathrm{~h}$ at $4^{\circ} \mathrm{C}$ and precipitated with streptavidin-sepharose beads. The precipitates were subjected to western blotting with anti-IRP1 or anti-IRP2 antibody (pull-down). Whole-cell lysates were also analyzed by western blotting (WB) for expression of IRP1, IRP2, TfR1, and $\beta$-actin (loading control). Experiments were repeated three times and representative blots are shown. $(C)$ Two hundred nanograms of pGL3-Promoter firefly luciferase plasmid containing wild-type IREs A-E (WT), mutant IRE C (mutC), mutant IRE E (mutE), or mutant IRE C and IRE E (mutC/E), were cotransfected with 10 ng pRL-SV40 Renilla luciferase vector into SW480 cells. The day after transfection, cells were treated with 0 or $250 \mu \mathrm{M}$ FAC for 18-24 h. Cells were harvested and luciferase assay was performed. Firefly luciferase activity was normalized to Renilla luciferase activity. Means \pm SE from four independent experiments are shown. $\left(^{*}\right) P<0.001$ versus no treatment. $(D)$ Twenty nanograms of pMIR-REPORT-WT or pMIR-REPORT-mutant IRE C/E luciferase plasmid were cotransfected with 20-40 ng pMIR-REPORT- $\beta$-galactosidase plasmid together with either 40 pmol of nontargeting siCon or 20 pmol each of miR-7-5p and miR-141-3p. After 0 (-) or $250(+) \mu \mathrm{M} \mathrm{FAC} \mathrm{treatment} \mathrm{for} 6 \mathrm{~h}$, cells were harvested and luciferase assay was performed. Luciferase activity was normalized to $\beta$-galactosidase activity. Means \pm SD from eight independent experiments are shown.

antagomiRs (Fig. 4D). As IRPs are bound to IREs to protect TfR1 mRNA from degradation, we also performed knockdown of IRPs to induce TfR1 mRNA degradation and tested the protection by antagomiR-7 and -141. As shown in Figure $4 \mathrm{E}$, knocking down IRPs mimicked the iron effect on the decrease in TfR1 mRNA and that was partially but significantly protected by antagomiR-7 and -141 . Furthermore, quantitation of endogenous miR-7 and miR-141 showed that the expression of these miRNAs was unchanged in iron-treated SW480 cells (Fig. 4F), ruling out the possibility that iron-induced miR-7 and miR-141 expression facilitates the attack of the TfR1 IREs.

\section{Correlation between miR-7 and TfR1 mRNA levels in human pancreatic adenocarcinomas}

Higher expression of TfR 1 allows cells to utilize more iron for cell proliferation and metabolism. Indeed some types of cancer cells express elevated levels of TfR1 (Ryschich et al. 2004;
Prutki et al. 2006; Habashy et al. 2010; Chan et al. 2014), although the mechanisms behind TfR1 overexpression in cancer cells may be complex and not well characterized. As a fraction of TfR 1 mRNA devoid of IRPs binding can be constantly attacked by miR-7-5p or miR-141-3p, we investigated whether expression levels of these miRNAs may correlate with TfR1 mRNA expression in cancers. We searched data sets in OncoLnc and found that there is an inverse correlation between expression levels of miR-7, but not miR-141, and TfR1 mRNA in pancreatic adenocarcinoma (PAAD) patient sample set from The Cancer Genome Atlas (TCGA) (Fig. $5 A)$. In this PAAD cohort, the higher expression levels of TfR1 mRNA were correlated with shorter survival of patients (Fig. 5B).

\section{DISCUSSION}

Determining the molecular mechanism of iron-induced TfR1 mRNA destabilization is an important question in iron 
A

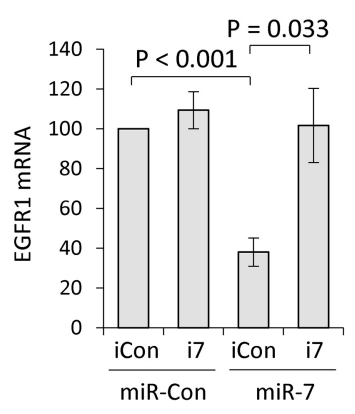

B
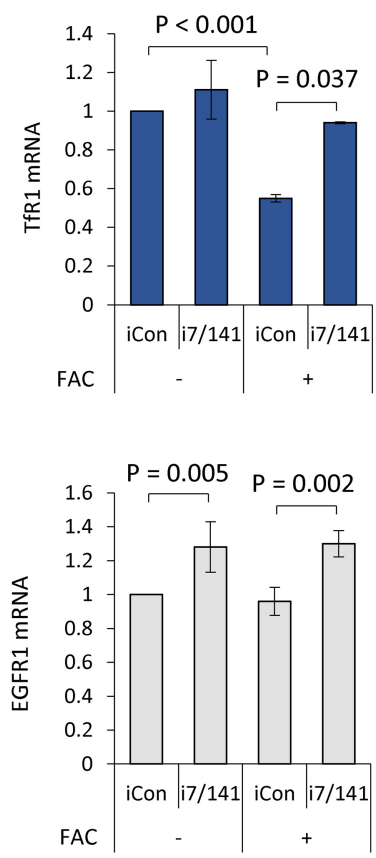

C
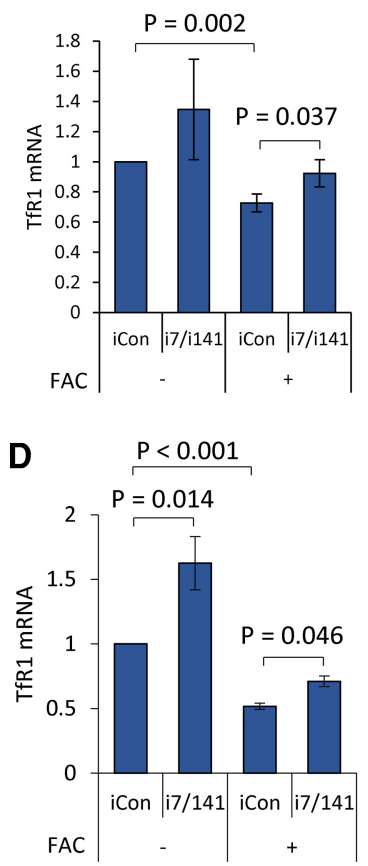

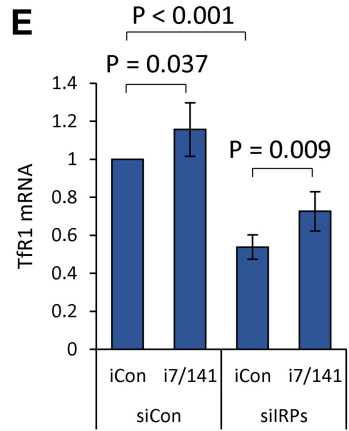

$\mathbf{F}$

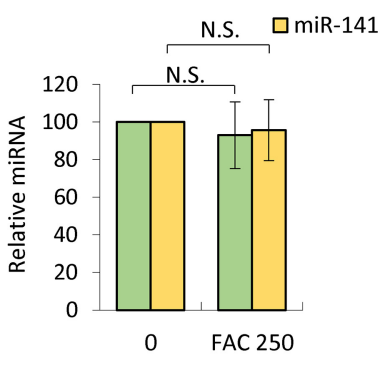

FIGURE 4. Blocking endogenous miR-7-5p and miR-141-3p increases TfR1 mRNA. (A) EGFR1 mRNA expression (normalized to HPRT1 expression) was measured in SW480 cells transfected with a combination of 20 pmol miR control (miR-Con) or miR-7-5p (miR-7) and 100 pmol antagomiR control (iCon) or antagomiR for miR-7-5p (i7). Means \pm SE from three independent experiments are shown. SW480 (B,C) or NIH3T3 (D) cells were transfected with 200 pmol iCon or 100 pmol each antagomiR for miR-7-5p, miR-141-3p (i7/141 in $B$ from Dharmacon, in $C$ from Qiagen). After 48 h, cells were treated with $250 \mu \mathrm{M}$ FAC for $2 \mathrm{~h}$ for SW480 or $1.5 \mathrm{~h}$ for NIH3T3 cells, and TfR1 or EGFR1 mRNA expression was measured by qPCR and normalized to HPRT1 expression. Means \pm SD from three to five independent experiments are shown. (E) SW480 cells were transfected with a combination of 40 pmol siRNA control (siCon) or siIRP1 and 2 (silRPs) and 100 pmol of iCon or i7/141. TfR1 mRNA was measured and normalized by HPRT1 mRNA expression. Means \pm SD from five independent experiments are shown. $(F)$ SW480 cells were treated with 0 or $250 \mu \mathrm{M}$ FAC for $24 \mathrm{~h}$, then mature miR-7-5p and miR-141-3p expressions were measured. Means \pm SE from three independent experiments are shown.

biology. While early studies suggested that TfR1 mRNA degradation began with an endonuclease cleavage at a specific site within the IRE region (Binder et al. 1994), a recent detailed study of the IRE region did not agree with these findings and described several new sequences contributing to TfR1 destabilization within the region containing IRE-B, -C, and -D (Rupani and Connell 2016). Importantly, this study also confirmed that TfR $1 \mathrm{mRNA}$ decay required some trans-acting factor, as TfR1 mRNA showed no evidence for autocatalytic or ribozyme activity (Rupani and Connell 2016).

Our study sought to determine what role, if any, miRNAs played in mediating TfR1 mRNA destabilization. We found that miR-7-5p and miR-141-3p target IRE C and IRE E, respectively, within the TfR1 3'-UTR. However, inhibitors of miR-7-5p and miR-141-3p did not completely prevent iron-induced degradation of TfR 1 mRNA, particularly in mouse cells (Fig. 4D), despite the conserved sequences of these miRNAs and targeted IRE sequences (Tables 1 and 2). There are a few possibilities explaining this observation. It is plausible that there is an alternative degradation pathway that is either the primary TfR $1 \mathrm{mRNA}$ degradation pathway (i.e., TfR $1 \mathrm{mRNA}$ is preferentially degraded by this pathway rather than by the miRNA pathway) or acts as a redundant degradation system (i.e., it degrades TfR1 mRNA if the miRNA pathway is inhibited). We considered several other options as the potential mechanism of TfR 1 mRNA degradation under high iron conditions. Firstly, it may be possible that there are other miRNAs involved in controlling TfR1 mRNA stability. In fact, miR-320 (Schaar et al. 2009), miR210 (Yoshioka et al. 2012), and miR-152 (Kindrat et al. 2016) were recently shown to target TfR1 mRNA, albeit far outside the IRE region, and appear unrelated to iron-induced destabilization of TfR1 mRNA. Regulation of TfR1 mRNA stability in high and low iron conditions is incredibly well conserved throughout vertebrate evolution. The three miRNAs investigated in this study were selected for multiple reasons: their target sites are located entirely within an IRE stem-loop; their target sequences are conserved throughout vertebrate evolution; and these miRNAs are ubiquitously expressed and conserved in vertebrates. However, there may be other miRNAs predicted to target within the $\sim 700 \mathrm{nt}$ IRE region. This is not uncommon as miRNA prediction algorithms heavily weight complementarity to the $6-8 \mathrm{nt}$ seed sequence in their predictions. In fact, miR-124, miR-7, and miR-141 target IRE-B, IRE-C, and IRE-E, respectively, whereas IRE-D together with IRE-B and IRE-C seem to be 

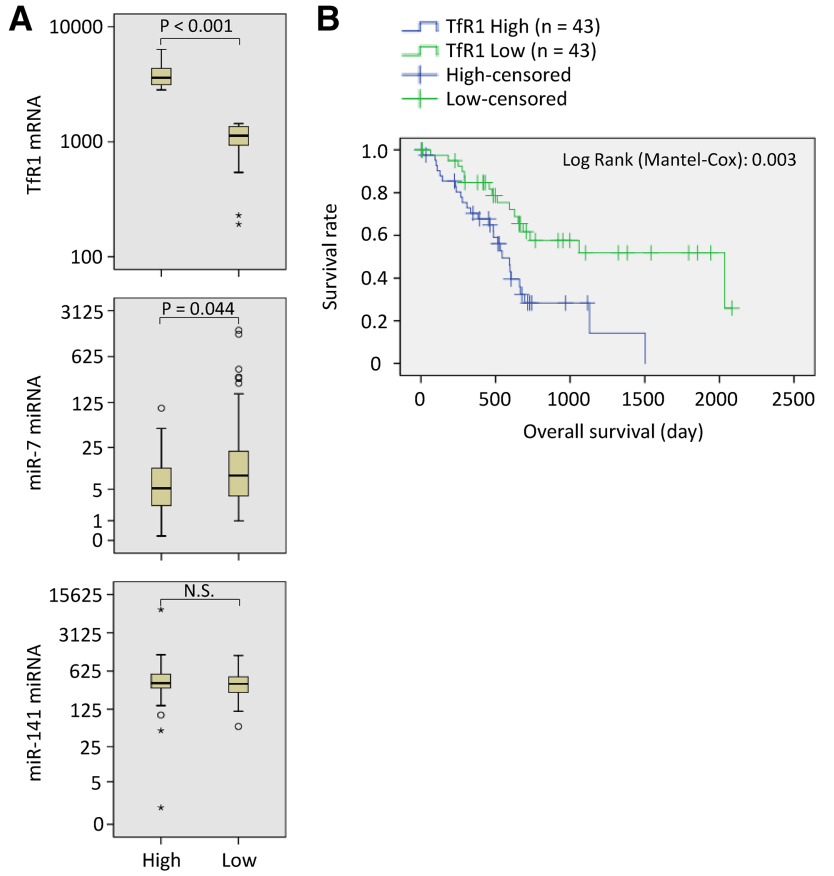

FIGURE 5. Relationship between miR-7 and TfR1 mRNA levels in human pancreatic adenocarcinomas. (A) miR-7-5p and miR-141-3p expression levels were compared based on TfR1 mRNA expression levels (top 25\%: high; bottom 25\%: low) of the pancreatic adenocarcinoma patient data set in OncoLnc. The data were analyzed by MannWhitney $U$-test and presented with a box plot format. $(B)$ The correlation of overall survival time and TfR 1 mRNA expression was analyzed using the two groups with high (top 25\%) and low (bottom 25\%) TfR1 mRNA level. The Kaplan-Meier curve was evaluated by the logrank (Mantel-Cox) test.

more important than IRE-A and IRE-E for regulation of the TfR1 mRNA stability (Casey et al. 1989). On the other hand, all five IREs in the TfR1 mRNA were shown to increase IRP1 and IRP2 binding compared to lower IRE copy numbers (three IREs containing B, C, and D, or two IREs containing $\mathrm{B}$ and $\mathrm{C}$ ) and more efficiently protect TfR1 mRNA from nuclease attack in vitro (Erlitzki et al. 2002). Any additional miRNAs and their binding sites in the TfR1 mRNA must be experimentally tested to determine if it is a bona fide target. Since regulation of TfR1 mRNA stability through the IRP-IRE system is well conserved throughout vertebrate evolution, we anticipate that an alternative destabilization mechanism through the IRE sequences should also be conserved in many species.

Secondly, there are many non-miR mRNA degradation systems involving myriad protein types, including endonucleases, exonucleases, decapping enzymes, RNA helicases, and others (Garneau et al. 2007; Schoenberg and Maquat 2012). For example, AU-rich elements (AREs) are sequences found within the $3^{\prime}$-UTR centered around the pentamer AUUUA that bind ARE-binding proteins (e.g., HuR, AUF1, and TTP), which in turn recruit other proteins to stabilize or destabilize the transcript (Schoenberg and Maquat 2012).
The TfR1 3'-UTR contains several putative AU-rich elements. A recent study uncovered a role for TTP (tristetraprolin) to destabilize TfR1 mRNA (Bayeva et al. 2012); however, this study concluded that TTP activity was activated by iron deficiency rather than iron excess and seems to be separate from the IRE-IRP system. A follow-up study highlighted the importance of a TTP-family protein (ZFP36L3) in TfR1 regulation during development (Stumpo et al. 2016). However, it seems that Zfp36L3 expresses only in specific tissues (yolk sac and placenta) in certain rodents (rats and mice), while the IRP-IRE system is ubiquitous across vertebrates. In addition, it demonstrated that deletion of the Zfp36l3 in mice stabilized TfR1 mRNA, but counterintuitively, significantly decreased overall TfR1 mRNA expression (Stumpo et al. 2016), highlighting the complexity of TfR1 expression regulation.

Some other mRNA degradation pathways, such as those initiated by endonucleases, are also sequence-specific. The recent study by Rupani and Connell (2016) granted insight into which sequences within the IRE region contribute to TfR1 mRNA instability, and may aid in developing testable hypotheses to determine the identity of additional TfR 1 degradation effector molecules. In this regard, it has recently been reported that regnase-1, an endonuclease attacking Pyr-Pur-Pyr-containing stem-loops (Matsushita et al. 2009; Uehata and Akira 2013), can degrade TfR1 mRNA by targeting a region located between IRE-B and IRE-C (Yoshinaga et al. 2017). However, the mechanism of TfR1 mRNA degradation by regnase- 1 was not further investigated in this work but it may not be able to explain the TfR1 mRNA destabilization mechanism within the IRP-IRE context because of no clear evidence for protection of TfR1 mRNA degradation by IRPs (Yoshinaga et al. 2017).

Given that iron induces degradation of TfR1 mRNA, we tested the possibility that iron may induce expression of miR-7 and miR-141 that can facilitate to attack TfR1 mRNA for degradation. However, iron treatment showed no effect on miR-7 and miR-141 expression levels (Fig. 4F). Although it is still in the early stages for our understanding of the regulatory mechanisms of individual miRNA expression, it was shown that miR-7 was increased by estrogen (Masuda et al. 2012), oleic acid (Kumar et al. 2017), and curcumin (Feng et al. 2017) in some cancer cells, while miR-141/ 200 expression was induced by oxidative stress such as hydrogen peroxide (Magenta et al. 2011; Mateescu et al. 2011). It is obvious that the regulation of IRP-IRE interactions by cellular iron status governs the stability of TfR1 mRNA; however, it is conceivable that expression changes in these miRNAs in response to environmental cues and in different tissues ultimately determine the stability of TfR1 mRNA and cellular iron metabolism.

Determining the molecular mechanism of iron-mediated TfR1 mRNA destabilization has broad implications. Altered iron metabolism, including high TfR1 expression even during iron overload, is a hallmark of many types of cancer 
(Torti and Torti 2013; Bogdan et al. 2016). Indeed, we observed the inverse relationship between miR-7 and TfR1 mRNA expression that also correlates with patient's survival in human pancreatic adenocarcinomas (Fig. 5). miR-7, frequently down-regulated in several types of cancers, plays a tumor suppressor role through repression of growthpromoting genes including EGFR (Horsham et al. 2015). We propose that TfR1 is another target of miR-7 as well as miR-141/200 for their tumor suppressor roles. Accordingly, targeting TfR1 expression in tumors has been attempted and remains an attractive therapeutic option (Jones et al. 2006; Daniels et al. 2012; Byrne et al. 2013). By complete understanding of the pathway by which iron destabilizes TfR1 mRNA, more treatment avenues are uncovered; reactivating the normal destabilization pathway to down-regulate TfR1 expression in malignant cells may be an effective treatment strategy in many cancer types.

\section{MATERIALS AND METHODS}

\section{Cell culture and reagents}

SW480 human colon adenocarcinoma cells (ATCC) were cultured in DMEM/high glucose supplemented with $10 \%$ fetal bovine serum (FBS, Mediatech, 35-010-CV). K562 human erythroleukemia cells (ATCC) were cultured in RPMI 1640 medium containing 10\% FBS. NIH3T3 mouse fibroblasts (ATCC) were cultured in DMEM/high glucose supplemented with $10 \%$ bovine calf serum (HyClone). Cells were maintained at $37^{\circ} \mathrm{C}$ in a humidified $5 \%$ $\mathrm{CO}_{2}$ incubator (Sanyo). Ferric ammonium citrate [FAC, also called ammonium iron(III) citrate; Sigma-Aldrich] and deferoxamine mesylate (DFO; Sigma-Aldrich) were dissolved in water. 5,6dichloro-1- $\beta$-D-ribofuranosyl-1H-benzimidazole (DRB; Cayman Chemicals) was dissolved in DMSO.

\section{Gene expression}

For protein expression analysis, whole-cell lysate was prepared in lysis buffer $\left(10 \mathrm{mM} \mathrm{Na}_{2} \mathrm{HPO}_{4}, 150 \mathrm{mM} \mathrm{NaCl}, 1 \%\right.$ Triton X-100, $0.5 \%$ sodium deoxycholate, $0.1 \%$ sodium dodecyl sulfate, $0.2 \%$ sodium azide). Lysates were run on SDS-PAGE, transferred to PVDF membranes (Thermo Fisher), blocked with 5\% skim milk in Tris-buffered saline (TBS) $/ 0.1 \%$ Tween-20, and incubated with primary antibody overnight at $4^{\circ} \mathrm{C}$. Western blotting antibodies: TfR1Zymed (13-6800); ferritin H-Santa Cruz (sc-25617); IRP1Santa Cruz (sc-14216); IRP2-Santa Cruz (sc-33682).

For mRNA expression analysis, total RNA was isolated using TRI Reagent RT (Molecular Research Center, Inc.). cDNA was reverse transcribed from $300 \mathrm{ng}$ total RNA using the iScript cDNA Synthesis Kit (Bio-Rad) according to the manufacturer's protocol. cDNA was used in quantitative PCR (qPCR) to determine the expression of target genes. qPCR reagents (iTaq Universal SYBR Green Supermix) and thermocycler (CFX96) were from Bio-Rad. qPCR primer sequences were obtained from PrimerBank (TfR1, EGFR1) or realtimeprimers.com (GAPDH, HPRT1), and primer oligos were obtained from Sigma-Aldrich:

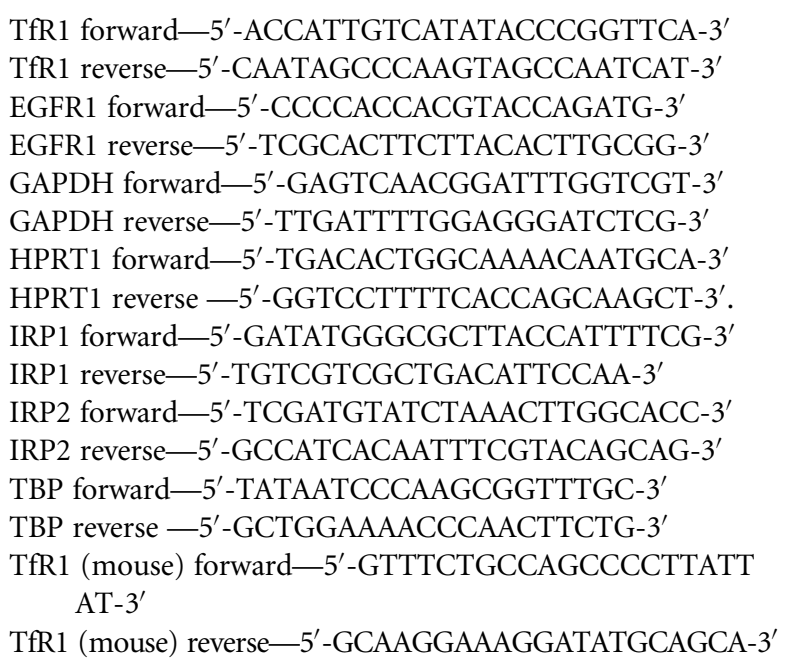

For microRNA quantitation, miR-7-5p, and miR-141-3p expression were measured by performing miRNA-specific reverse transcription (miScript RT II Kit, Qiagen) and quantitative PCR using miScript Primer Assays (miR-7: \#MS00032116; miR-141: \#MS00003507; U6 loading control: \#MS00033740, Qiagen) according to the manufacturer's protocol.

\section{siRNA, microRNA mimics and antagomiRs}

siControl (Silencer Negative Control No. 1) was purchased from Ambion. miR-124-3p (C-300592-05, 5'-UAAGGCACGCGGUGA AUGCC-3'), miR-7-5p (C-300547-05, 5'-UGGAAGACUAGUGA UUUUGUUGU- $3^{\prime}$ ), and miR-141-3p mimics (C-300608-03, $5^{\prime}-$ UAACACUGUCUGGUAAAGAUGG-3') were purchased from Dharmacon. Syn-hsa-miR-7-5p (MSY0000252, 5'-UGGAAGAC UAGUGAUUUUGUUGU-3') and Syn-hsa-miR-141-3p (MSY00 00432, 5' -UAACACUGUCUGGUAAAGAUGG-3') were purchased from Qiagen. AntagomiR negative control (IN-001005-01, miRIDIAN microRNA Hairpin Inhibitor Negative Control \#1, sequence not provided), anti-miR-124-3p (IH-300592-06), antimiR-7-5p (IH-300547-06), and anti-miR-141-3p (IH-300608-05) were from Dharmacon. In Figure $4 \mathrm{C}$, we used antagomiRs from Qiagen: i-Con (negative control, Cat.\#1027272), anti-miR-7-5p (Cat.\#MIN0000252), and anti-miR-141-3p (Cat.\#MIN0000432). siRNAs for IRP1 (Cat.\#1027423, target sequences: $5^{\prime}$-AAGGGCAAG AACGATACACTA-3' and 5'-AACCATAAGACCTTTATCTAT-3') and IRP2 (Cat.\#1027423, target sequence: 5'-AAGGAAGAACAT GTTATACTA- $3^{\prime}$ ) were purchased from Qiagen.

For miR mimic transfection, $25 \mathrm{pmol}$ of mimic were transfected into SW480 or K562 cells using Lipofectamine RNAiMAX (Invitrogen) $2 \mathrm{~d}$ prior to treatment or harvest. For antagomiR transfection, 200 pmol of antagomiR were transfected using Lipofectamine RNAiMAX $2 \mathrm{~d}$ prior to treatment or harvest. For cotransfection of miR and antagomiR, $25 \mathrm{pmol} \mathrm{miR}$ and $200 \mathrm{pmol}$ antagomiR were transfected using Lipofectamine RNAiMAX. For cotransfection of siIRP1, siIRP2 and antagomiRs, 40 pmol each of two siIRP1 and one siIRP2 was transfected into SW480 cells in sixwell plate ( $2 \mathrm{~mL}$ media/well) with TransIT-X2 (Mirus) overnight, and 100 pmol each of antagomiR-7 and - 141 were sequentially transfected with Lipofectamine RNAiMAX for 16-24 h before harvesting total RNA. 


\section{IRE-IRP binding assays}

Ten micrograms of biotin-labeled TfR1 IRE C or E was incubated with $200 \mu \mathrm{g}$ of whole-cell extracts at room temperature for $2 \mathrm{~h}$ followed by precipitation of IRE-protein complexes with streptavidinsepharose beads. The precipitates were washed three times with 1 $\mathrm{mL}$ of modified-RIPA buffer $(25 \mathrm{mM}$ Tris $\mathrm{pH} 7.4,15 \mathrm{mM} \mathrm{NaCl}$, $1 \%$ NP-40, $0.5 \%$ sodium deoxycholate) and subjected to western blotting with anti-IRP1 or anti-IRP2 antibody.

\section{Luciferase assays}

A $~ 700$ bp fragment containing the five IREs from the TfR1 3 '-UTR was generated from the TfR1 $3^{\prime}$-UTR via PCR using the following primers:

\section{forward-5' ${ }^{\prime}$-AATTTCTAGATAGGGGAGAGCTTTCTGTC-3';} reverse-5'-AATTTCTAGAAGGGAATTATAGGAGTTGGG-3' .

These primers contain $\mathrm{XbaI}$ digestion sites, which were used to insert the IRE-containing fragment into the XbaI site downstream from the luciferase gene in the pGL3-Promoter plasmid (Promega). This insert was then subcloned into pMIR-REPORT luciferase vector (Ambion) for use in luciferase/microRNA cotransfection experiments. Insert orientation and sequence were validated via DNA sequencing. For pGL3-Promoter experiments, Renilla luciferase vector (Promega) was cotransfected as a normalization control. For pMIR-REPORT experiments, $\beta$-galactosidase (pMIR-REPORT $\beta$-galactosidase Control Vector, Ambion) was cotransfected as a normalization control. Single and dual luciferase assays (Promega) were performed in accordance with manufacturer's protocol and measured on a GloMax 20/20 luminometer (Promega). $\beta$-Galactosidase activity was measured according to the manufacturer's protocol (Ambion).

\section{Generation of mutant IRE-luciferase vectors}

Mutations were inserted into the wild-type pGL3-Promoter-5xIRE using the QuikChange II Site-directed Mutagenesis Kit (Agilent Technologies) according to the manufacturer's protocol, with the addition of GC Melt (Clontech, 10\% final concentration) to the reaction mixture. The following primers (Sigma-Aldrich) were used:

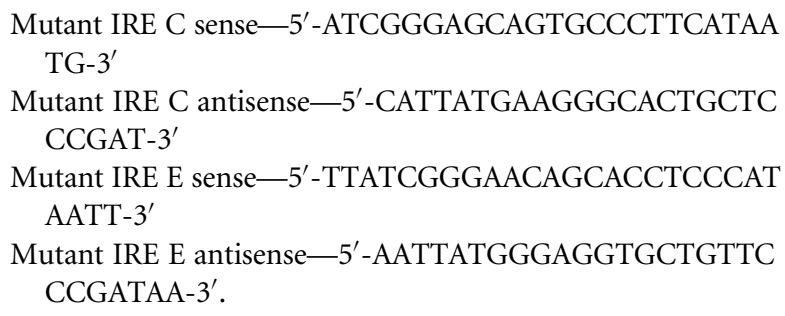
CCGAT-3'

Mutant IRE E sense- $5^{\prime}$-TTATCGGGAACAGCACCTCCCAT AATT- $3^{\prime}$

Mutant IRE E antisense-5'-AATTATGGGAGGTGCTGTTC CCGATAA-3'.

The IRE C/E double mutant vector was generated by performing the mutagenesis reaction on the mutant IRE $C$ vector using mutant IRE E primers. All mutants were confirmed by DNA sequencing.

\section{Statistics}

Results in Figures $1-4$ were analyzed by one-way analysis of variance (ANOVA), and $P$-values were assigned by using the Fisher's least sig- nificant difference (LSD) test. Differences among means were considered statistically significant when the $P$-value is $<0.05$. SPSS Statistics 24 software (IBM) was used for all statistics analysis. The data set of the human pancreatic adenocarcinoma samples were analyzed by Mann-Whitney $U$-test and presented with a box plot format.

\section{SUPPLEMENTAL MATERIAL}

Supplemental material is available for this article.

\section{ACKNOWLEDGMENTS}

Alexander R. Bogdan was supported by National Institutes of Health Training Grant T32ES007046 from the National Institute of Environmental Health Sciences. This work was supported by the NIH grant R01GM088392 from the National Institute of General Medical Sciences to Y.T. and in part by P30ES025128 from the National Institute of Environmental Health Sciences to Center for Human Health and the Environment (CHHE).

Received September 7, 2017; accepted December 21, 2017.

\section{REFERENCES}

Agarwal V, Bell GW, Nam JW, Bartel DP. 2015. Predicting effective microRNA target sites in mammalian mRNAs. Elife 4: e05005.

Anderson CP, Shen M, Eisenstein RS, Leibold EA. 2012. Mammalian iron metabolism and its control by iron regulatory proteins. Biochim Biophys Acta 1823: 1468-1483.

Bayeva M, Khechaduri A, Puig S, Chang HC, Patial S, Blackshear PJ, Ardehali H. 2012. mTOR regulates cellular iron homeostasis through tristetraprolin. Cell Metab 16: 645-657.

Binder R, Horowitz JA, Basilion JP, Koeller DM, Klausner RD, Harford JB. 1994. Evidence that the pathway of transferrin receptor mRNA degradation involves an endonucleolytic cleavage within the $3^{\prime}$ UTR and does not involve poly(A) tail shortening. EMBO J 13: 1969-1980.

Bogdan AR, Miyazawa M, Hashimoto K, Tsuji Y. 2016. Regulators of iron homeostasis: new players in metabolism, cell death, and disease. Trends Biochem Sci 41: 274-286.

Brennecke J, Stark A, Russell RB, Cohen SM. 2005. Principles of microRNA-target recognition. PLoS Biol 3: e85.

Bridges KR, Cudkowicz A. 1984. Effect of iron chelators on the transferrin receptor in K562 cells. J Biol Chem 259: 12970-12977.

Byrne SL, Buckett PD, Kim J, Luo F, Sanford J, Chen J, Enns C, Wessling-Resnick M. 2013. Ferristatin II promotes degradation of transferrin receptor-1 in vitro and in vivo. PLoS One 8: e70199.

Casey JL, Hentze MW, Koeller DM, Caughman SW, Rouault TA, Klausner RD, Harford JB. 1988. Iron-responsive elements: regulatory RNA sequences that control mRNA levels and translation. Science 240: 924-928.

Casey JL, Koeller DM, Ramin VC, Klausner RD, Harford JB. 1989. Iron regulation of transferrin receptor mRNA levels requires iron-responsive elements and a rapid turnover determinant in the $3^{\prime}$ untranslated region of the mRNA. EMBO J 8: 3693-3699.

Chan KT, Choi MY, Lai KK, Tan W, Tung LN, Lam HY, Tong DK, Lee NP, Law S. 2014. Overexpression of transferrin receptor CD71 and its tumorigenic properties in esophageal squamous cell carcinoma. Oncol Rep 31: 1296-1304.

Daniels TR, Bernabeu E, Rodriguez JA, Patel S, Kozman M, Chiappetta DA, Holler E, Ljubimova JY, Helguera G, Penichet ML. 2012. The transferrin receptor and the targeted 
delivery of therapeutic agents against cancer. Biochim Biophys Acta 1820: 291-317.

Dixon SJ, Stockwell BR. 2014. The role of iron and reactive oxygen species in cell death. Nat Chem Biol 10: 9-17.

Erlitzki R, Long JC, Theil EC. 2002. Multiple, conserved iron-responsive elements in the $3^{\prime}$-untranslated region of transferrin receptor mRNA enhance binding of iron regulatory protein 2. J Biol Chem 277: $42579-42587$.

Fabian MR, Sonenberg N. 2012. The mechanics of miRNA-mediated gene silencing: a look under the hood of miRISC. Nat Struct Mol Biol 19: 586-593.

Feng S, Wang Y, Zhang R, Yang G, Liang Z, Wang Z, Zhang G. 2017. Curcumin exerts its antitumor activity through regulation of miR7/Skp2/p21 in nasopharyngeal carcinoma cells. Onco Targets Ther 10: $2377-2388$.

Garneau NL, Wilusz J, Wilusz CJ. 2007. The highways and byways of mRNA decay. Nat Rev Mol Cell Biol 8: 113-126.

Ghezzi P, Jaquet V, Marcucci F, Schmidt H. 2017. The oxidative stress theory of disease: levels of evidence and epistemological aspects. $\mathrm{Br}$ J Pharmacol 174: 1784-1796.

Habashy HO, Powe DG, Staka CM, Rakha EA, Ball G, Green AR, Aleskandarany M, Paish EC, Douglas Macmillan R, Nicholson RI, et al. 2010. Transferrin receptor (CD71) is a marker of poor prognosis in breast cancer and can predict response to tamoxifen. Breast Cancer Res Treat 119: 283-293.

Hayes J, Peruzzi PP, Lawler S. 2014. MicroRNAs in cancer: biomarkers, functions and therapy. Trends Mol Med 20: 460-469.

Hentze MW, Muckenthaler MU, Galy B, Camaschella C. 2010. Two to tango: regulation of mammalian iron metabolism. Cell 142: 24-38.

Horsham JL, Ganda C, Kalinowski FC, Brown RA, Epis MR, Leedman PJ. 2015. MicroRNA-7: a miRNA with expanding roles in development and disease. Int J Biochem Cell Biol 69: 215-224.

Iwakawa HO, Tomari Y. 2015. The functions of microRNAs: mRNA decay and translational repression. Trends Cell Biol 25: 651-665.

Jomova K, Valko M. 2011. Advances in metal-induced oxidative stress and human disease. Toxicology 283: 65-87.

Jones DT, Trowbridge IS, Harris AL. 2006. Effects of transferrin receptor blockade on cancer cell proliferation and hypoxia-inducible factor function and their differential regulation by ascorbate. Cancer Res 66: 2749-2756.

Kindrat I, Tryndyak V, de Conti A, Shpyleva S, Mudalige TK, Kobets T, Erstenyuk AM, Beland FA, Pogribny IP. 2016. MicroRNA-152-mediated dysregulation of hepatic transferrin receptor-1 in liver carcinogenesis. Oncotarget 7: 1276-1287.

Kühn LC. 2015. Iron regulatory proteins and their role in controlling iron metabolism. Metallomics 7: 232-243.

Kumar S, Downie Ruiz Velasco A, Michlewski G. 2017. Oleic acid induces miR-7 processing through remodeling of pri-miR-7/protein complex. J Mol Biol 429: 1638-1649.

Lambert LA. 2012. Molecular evolution of the transferrin family and associated receptors. Biochim Biophys Acta 1820: 244-255.

Lewis BP, Burge CB, Bartel DP. 2005. Conserved seed pairing, often flanked by adenosines, indicates that thousands of human genes are microRNA targets. Cell 120: 15-20.

MacKenzie EL, Iwasaki K, Tsuji Y. 2008. Intracellular iron transport and storage: from molecular mechanisms to health implications. Antioxid Redox Signal 10: 997-1030.

Magenta A, Cencioni C, Fasanaro P, Zaccagnini G, Greco S, SarraFerraris G, Antonini A, Martelli F, Capogrossi MC. 2011. miR$200 \mathrm{c}$ is upregulated by oxidative stress and induces endothelial cell apoptosis and senescence via ZEB1 inhibition. Cell Death Differ 18: $1628-1639$.

Masuda M, Miki Y, Hata S, Takagi K, Sakurai M, Ono K, Suzuki K, Yang Y, Abe E, Hirakawa $\mathrm{H}$, et al. 2012. An induction of microRNA, miR-7 through estrogen treatment in breast carcinoma. J Transl Med 10(Suppl 1): S2.
Mateescu B, Batista L, Cardon M, Gruosso T, de Feraudy Y, Mariani O, Nicolas A, Meyniel JP, Cottu P, Sastre-Garau X, et al. 2011. miR-141 and miR-200a act on ovarian tumorigenesis by controlling oxidative stress response. Nat Med 17: 1627-1635.

Matsushita K, Takeuchi O, Standley DM, Kumagai Y, Kawagoe T, Miyake T, Satoh T, Kato H, Tsujimura T, Nakamura $\mathrm{H}$, et al. 2009. Zc3h12a is an RNase essential for controlling immune responses by regulating mRNA decay. Nature 458: 1185-1190.

Mattia E, Rao K, Shapiro DS, Sussman HH, Klausner RD. 1984. Biosynthetic regulation of the human transferrin receptor by desferrioxamine in K562 cells. J Biol Chem 259: 2689-2692.

Muckenthaler MU, Rivella S, Hentze MW, Galy B. 2017. A red carpet for iron metabolism. Cell 168: 344-361.

Müllner EW, Kühn LC. 1988. A stem-loop in the 3' untranslated region mediates iron-dependent regulation of transferrin receptor mRNA stability in the cytoplasm. Cell 53: 815-825.

Müllner EW, Neupert B, Kühn LC. 1989. A specific mRNA binding factor regulates the iron-dependent stability of cytoplasmic transferrin receptor mRNA. Cell 58: 373-382.

Owen D, Kuhn LC. 1987. Noncoding 3' sequences of the transferrin receptor gene are required for mRNA regulation by iron. EMBO J 6: 1287-1293.

Piccinelli P, Samuelsson T. 2007. Evolution of the iron-responsive element. RNA 13: 952-966.

Poprac P, Jomova K, Simunkova M, Kollar V, Rhodes CJ, Valko M. 2017. Targeting free radicals in oxidative stress-related human diseases. Trends Pharmacol Sci 38: 592-607.

Prutki M, Poljak-Blazi M, Jakopovic M, Tomas D, Stipancic I, Zarkovic N. 2006. Altered iron metabolism, transferrin receptor-1 and ferritin in patients with colon cancer. Cancer Lett 238: 188-196.

Rao KK, Shapiro D, Mattia E, Bridges K, Klausner R. 1985. Effects of alterations in cellular iron on biosynthesis of the transferrin receptor in K562 cells. Mol Cell Biol 5: 595-600.

Ray PD, Huang BW, Tsuji Y. 2012. Reactive oxygen species (ROS) homeostasis and redox regulation in cellular signaling. Cell Signal 24: 981-990.

Rouault TA. 2006. The role of iron regulatory proteins in mammalian iron homeostasis and disease. Nat Chem Biol 2: 406-414.

Rouault T, Rao K, Harford J, Mattia E, Klausner RD. 1985. Hemin, chelatable iron, and the regulation of transferrin receptor biosynthesis. $J$ Biol Chem 260: 14862-14866.

Rouault TA, Hentze MW, Caughman SW, Harford JB, Klausner RD. 1988. Binding of a cytosolic protein to the iron-responsive element of human ferritin messenger RNA. Science 241: 1207-1210.

Rupani DN, Connell GJ. 2016. Transferrin receptor mRNA interactions contributing to iron homeostasis. RNA 22: 1271-1282.

Ryschich E, Huszty G, Knaebel HP, Hartel M, Büchler MW, Schmidt J. 2004. Transferrin receptor is a marker of malignant phenotype in human pancreatic cancer and in neuroendocrine carcinoma of the pancreas. Eur J Cancer 40: 1418-1422.

Salahudeen AA, Thompson JW, Ruiz JC, Ma HW, Kinch LN, Li Q, Grishin NV, Bruick RK. 2009. An E3 ligase possessing an iron-responsive hemerythrin domain is a regulator of iron homeostasis. Science 326: 722-726.

Schaar DG, Medina DJ, Moore DF, Strair RK, Ting Y. 2009. miR-320 targets transferrin receptor-1 (CD71) and inhibits cell proliferation. Exp Hematol 37: 245-255.

Schoenberg DR, Maquat LE. 2012. Regulation of cytoplasmic mRNA decay. Nat Rev Genet 13: 246-259.

Stumpo DJ, Trempus CS, Tucker CJ, Huang W, Li L, Kluckman K, Bortner DM, Blackshear PJ. 2016. Deficiency of the placenta- and yolk sac-specific tristetraprolin family member ZFP36L3 identifies likely mRNA targets and an unexpected link to placental iron metabolism. Development 143: 1424-1433.

Theil EC. 1994. Iron regulatory elements (IREs): a family of mRNA noncoding sequences. Biochem J 304(Pt 1): 1-11.

Torti SV, Torti FM. 2013. Iron and cancer: more ore to be mined. Nat Rev Cancer 13: 342-355. 
Uehata T, Akira S. 2013. mRNA degradation by the endoribonuclease Regnase-1/ZC3H12a/MCPIP-1. Biochim Biophys Acta 1829: 708-713.

Vashisht AA, Zumbrennen KB, Huang X, Powers DN, Durazo A, Sun D, Bhaskaran N, Persson A, Uhlen M, Sangfelt O, et al. 2009. Control of iron homeostasis by an iron-regulated ubiquitin ligase. Science 326: $718-721$.

Webster RJ, Giles KM, Price KJ, Zhang PM, Mattick JS, Leedman PJ. 2009. Regulation of epidermal growth factor receptor signaling in human cancer cells by microRNA-7. J Biol Chem 284: $5731-5741$.
Wilson BR, Bogdan AR, Miyazawa M, Hashimoto K, Tsuji Y. 2016. Siderophores in iron metabolism: from mechanism to therapy potential. Trends Mol Med 22: 1077-1090.

Yoshinaga M, Nakatsuka Y, Vandenbon A, Ori D, Uehata T, Tsujimura T, Suzuki Y, Mino T, Takeuchi O. 2017. Regnase-1 maintains iron homeostasis via the degradation of transferrin receptor-1 and prolyl-hydroxylase-domain-containing protein 3 mRNAs. Cell Rep 19: 1614-1630.

Yoshioka Y, Kosaka N, Ochiya T, Kato T. 2012. Micromanaging iron homeostasis: hypoxia-inducible micro-RNA-210 suppresses iron homeostasis-related proteins. J Biol Chem 287: 34110-34119. 

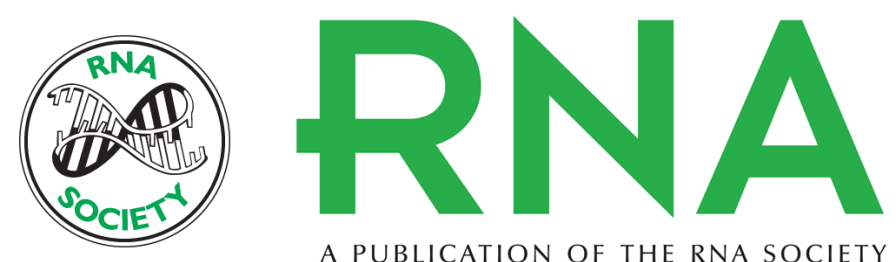

A PUBLICATION OF THE RNA SOCIETY

\section{Regulation of transferrin receptor-1 mRNA by the interplay between IRE-binding proteins and miR-7/miR-141 in the 3 '-IRE stem-loops}

Masaki Miyazawa, Alexander R. Bogdan, Kazunori Hashimoto, et al.

RNA 2018 24: 468-479 originally published online January 2, 2018

Access the most recent version at doi:10.1261/rna.063941.117

\section{Supplemental Material}

References

Creative Commons License

Email Alerting
Service
http://rnajournal.cshlp.org/content/suppl/2018/01/02/rna.063941.117.DC1

This article cites 62 articles, 16 of which can be accessed free at: http://rnajournal.cshlp.org/content/24/4/468.full.html\#ref-list-1

This article is distributed exclusively by the RNA Society for the first 12 months after the full-issue publication date (see http://rnajournal.cshlp.org/site/misc/terms.xhtml). After 12 months, it is available under a Creative Commons License (Attribution-NonCommercial 4.0 International), as described at http://creativecommons.org/licenses/by-nc/4.0/.

Receive free email alerts when new articles cite this article - sign up in the box at the top right corner of the article or click here.

To subscribe to $R N A$ go to:

http://rnajournal.cshlp.org/subscriptions 